\title{
Normative data for hand grip strength and key pinch strength, stratified by age and gender for a multiethnic Asian population
}

\author{
Ngee Wei $\underline{\mathrm{Lam}}^{1}$, MD, MMed, Hui Ting $\underline{G o h}^{2}$, PT, PhD, Shahrul Bahyah $\underline{\text { Kamaruzzaman }}^{3,4}$, MRCP, PhD, Ai-Vyrn $\underline{\text { Chin }}{ }^{3,4}$, MRCP, MD,
} Philip Jun Hua $\underline{P o}^{3,4}$, MRCP, Maw Pin $\underline{\operatorname{Tan}}^{3,4}$, MRCP, MD

\begin{abstract}
INTRODUCTION Hand strength is a good indicator of physical fitness and frailty among the elderly. However, there are no published hand strength references for Malaysians aged $>65$ years. This study aimed to establish normative data for hand grip strength (HGS) and key pinch strength (KPS) for Malaysians aged $\geq 60$ years, and explore the relationship between hand strength and physical ability.

METHODS Healthy participants aged $\geq 60$ years with no neurological conditions were recruited from rural and urban locations in Malaysia. HGS and KPS were measured using hand grip and key pinch dynamometers. Basic demographic data, anthropometric measures, modified Barthel Index scores and results of the Functional Reach Test (FRT), Timed Up and Go (TUG) test and Jebsen-Taylor Hand Function Test (JTHFT) were recorded.

RESULTS 362 subjects aged 60-93 years were recruited. The men were significantly stronger than the women in both HGS and KPS $(p<0.001)$. The hand strength of the study cohort was lower than that of elderly Western populations. Significant correlations were observed between hand strength, and residential area $(p<0.001), F R T(r=0.236, p=0.028)$, TUG $(r=-0.227, p=0.009)$ and JTHFT $(r=-0.927, p<0.001)$.

CONCLUSION This study established reference ranges for the HGS and KPS of rural and urban elderly Malaysian subpopulations. These will aid the use of hand strength as a screening tool for frailty among elderly persons in Malaysia. Future studies are required to determine the modifiable factors for poor hand strength.
\end{abstract}

Keywords: aged, frailty, functional impairment, hand strength

\section{INTRODUCTION}

The older population is more susceptible to disease and physical deconditioning following acute illness, with an increased risk of prolonged hospital stay, immobility, dependency and institutionalisation. ${ }^{(1)}$ The susceptibility of the older population to negative insults is dependent on their level of frailty. ${ }^{(2)}$ However, the ageing process and degree of frailty in older adults are modifiable with the help of appropriate strategies, to allow these individuals to live longer without severe disability. ${ }^{(3)}$ Hand grip strength (HGS), a well-established health indicator for frailty and risk of disability among the elderly, allows early risk identification and intervention. ${ }^{(4)}$ HGS is also a predictor of negative health outcomes, including mortality and hospital discharge outcome. . $^{(5-7)}$ Gale et al reported that each standard deviation (SD) increase in HGS was associated with a significant reduction in the relative risk of death from all causes, including cardiovascular disease and male cancer. ${ }^{(5)}$ A pilot study conducted on a cohort of older inpatients in a geriatric ward in Malaysia revealed that after adjustment for gender, age and height, HGS of the patients was negatively associated with length of hospital stay. ${ }^{(8)}$ HGS may, therefore, have the potential to be a prognostic indicator for acute hospital episodes, with the possibility of wider application. ${ }^{(9)}$

As HGS measurement is simple, noninvasive and relatively inexpensive, it may also be used to help determine appropriate interventions, measure response to therapy and manage healthcare resources. Since the publication of the first normative study for HGS in 1971, which lacked procedural standardisation, ${ }^{(10)}$ numerous normative studies have been performed over the last few decades in different countries and populations. ${ }^{(11-18)}$ Reported HGS norms in different populations varied significantly, suggesting that a universal norm does not exist. However, the aforementioned studies consistently demonstrated that HGS is significantly influenced by age, gender and body size. Nutritional status, lifestyle and occupation may also affect HGS. ${ }^{(19)}$ Nevertheless, previously published normative data on HGS for older adults was predominantly collected in Western populations and is unlikely to be applicable to Southeast Asia, whose populations have smaller stature and different genetics, lifestyles and occupations.

HGS normative data for Malaysians was published in 2006 by Kamarul et $\mathrm{al}^{(20)}$ who reported that the overall HGS of the Malaysian population was 1.5 times lower than that of Western populations. ${ }^{(20)}$ However, the study excluded individuals aged $>65$ years. To date, there are no standardised, normative values of HGS for Malaysians aged $\geq 60$ years, to the best of our knowledge. Thus, the primary purpose of the present study was to establish normative values of HGS and key pinch strength (KPS) for the older Malaysian population. The secondary aim

${ }^{1}$ Department of Medicine, Faculty of Medicine, University of Malaya, Malaysia, ${ }^{2}$ School of Physical Therapy, Texas Woman's University, Dallas, Texas, USA, ${ }^{3}$ Division of Geriatric Medicine, Department of Medicine, ${ }^{4}$ Ageing and Age-Associated Disorders Research Group, Faculty of Medicine, University of Malaya, Malaysia

Correspondence: Dr Tan Maw Pin, Associate Professor, Division of Geriatric Medicine, Department of Medicine, Faculty of Medicine, University of Malaya, 50603 Kuala Lumpur, Malaysia.mptan@ummc.edu.my 
was to evaluate the association between HGS and measures of physical ability.

\section{METHODS}

Individuals aged $\geq 60$ years were recruited from the urban area of Klang Valley, Selangor, Malaysia, and the rural town of Bahau, Negeri Sembilan, Malaysia, from February-September 2013. Participants were: (a) individuals who were recruited via word of mouth and/or media advertising; or (b) visitors to the inpatient and outpatient departments of University of Malaya Medical Centre, Kuala Lumpur, Malaysia, or persons attending community-based healthcare screening programmes who were approached by our research staff. The exclusion criteria were: (a) acute illness; (b) hospitalisation within the past month; (c) history of upper limb injury or deformity with motor impairment; (d) neurological disorders involving the hand (e.g. stroke, Parkinsonism and neurodegenerative disorders); or (e) a modified Barthel Index score $<90$. The study protocol was reviewed and approved by the University of Malaya Medical Centre's Medical Ethics Committee.

Basic demographic information and a brief medical history were recorded from each of the participants. Functional status was assessed using the modified Barthel Index. Healthy volunteers who attended a clinic visit were also assessed for their performance on the Jebsen-Taylor Hand Function Test (JTHFT), Functional Reach Test (FRT), and Timed Up and Go (TUG) test. These tests were not administered for the participants recruited from community health screening programmes due to time and resource limitations.

The Jamar hydraulic hand dynamometer (Patterson Medical, Warrenville, IL, USA) was used to measure HGS, while the Baseline ${ }^{\circledR}$ pinch gauge was used to measure KPS. The dynamometers were calibrated prior to the first measurement. Participants were seated on a standard height chair without armrests and positioned as per the American Society of Hand Therapists' recommendation. ${ }^{(21)}$ They were seated with one shoulder adducted and neutrally rotated, elbow flexed at $90^{\circ}$, forearm in a neutral position, and wrist in $0^{\circ}-30^{\circ}$ dorsiflexion and $0^{\circ}-15^{\circ}$ ulnar deviation. ${ }^{(21,22)}$ The grip handle of the dynamometer was adjusted based on the participant's hand size in order to obtain an optimal grip position (Fig. 1). The test was performed with standardised verbal instructions (i.e. "one, two, three, squeeze... harder... harder...") and participants were asked to use the non-dominant hand first, followed by the dominant hand. Three measurements of HGS were taken for each hand, with a 10-20-second rest between the measurements to avoid fatigue. The mean value of all three measurements was calculated. A similar procedure was performed to measure KPS. For KPS measurement, the Baseline pinch gauge was placed between the thumb and the lateral aspect of the index finger (Fig. 2). As the Baseline pinch gauge used in the present study malfunctioned toward the end of the data collection phase, fewer data points on KPS were collected ( $n=246$, instead of $\mathrm{n}=362$ )

Hand function was measured using the JTHFT, which consists of seven subtests to assess fine motor, non-weighted

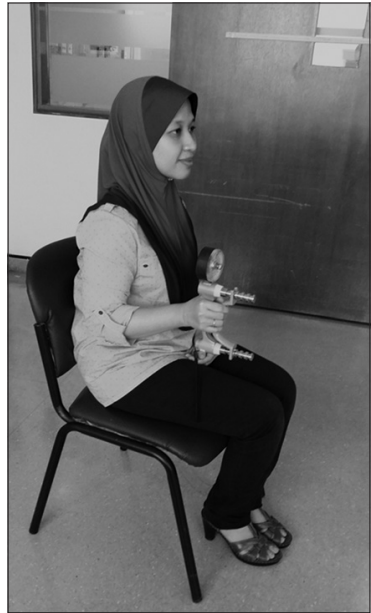

Fig. 1 Photograph shows the recommended standardised position during hand grip strength measurement.
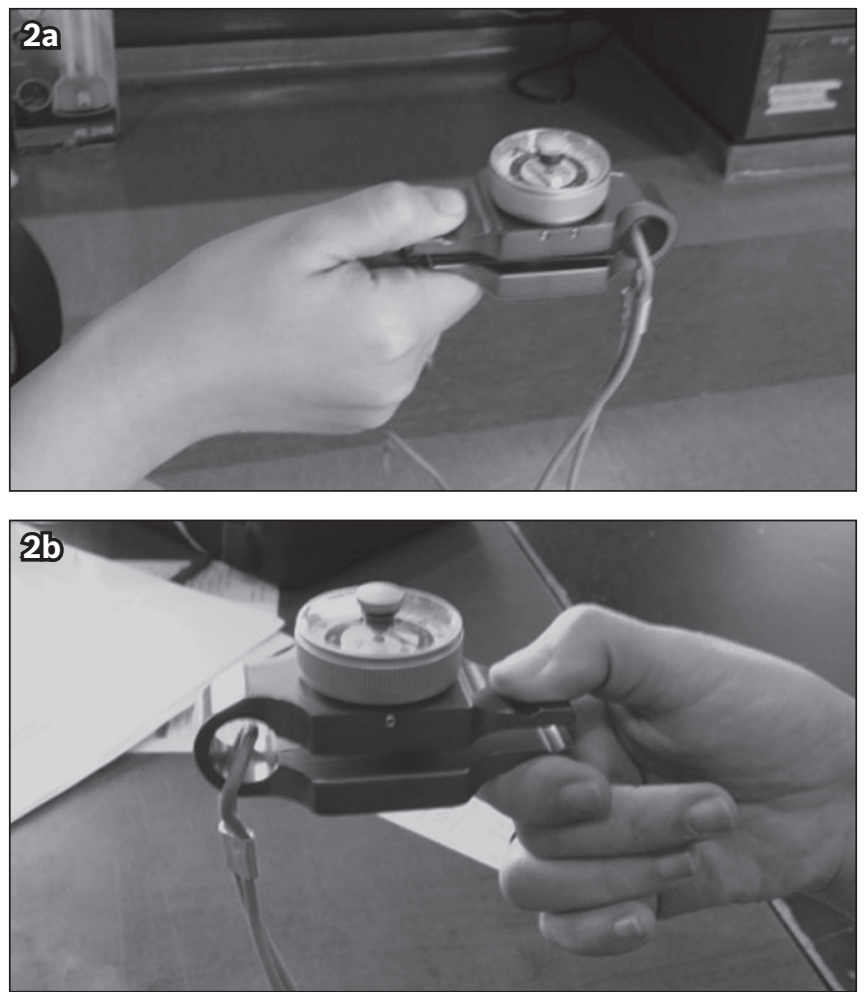

Fig. 2 Photographs show the position of the (a) thumb and (b) index finger for key pinch strength measurement.

and weighted hand functions with activities such as writing, card turning, picking up small common objects and placing them in a container, stacking checkers, simulated feeding, and moving light and heavy objects. All subtests were performed with standardised verbal instructions, starting with the nondominant hand and followed by the dominant hand. ${ }^{(23)}$ Duration (in seconds) required to complete each subtest was used to quantify the function; the maximum time allocated per subtest was 120 seconds. The total duration required for all the seven subtests was computed to yield the total score. Lower scores indicated greater levels of hand function. Static balance was measured using the FRT, ${ }^{(24)}$ which measures the maximum distance an individual can reach forward while standing in 
Table I. Characteristics of the participants.

\begin{tabular}{|c|c|c|c|}
\hline \multirow[t]{2}{*}{ Variable } & \multicolumn{3}{|c|}{ No. (\%) } \\
\hline & Female $(n=217)$ & Male $(n=145)$ & Total $(n=362)$ \\
\hline Age* (yr) $^{*}$ & $69.0 \pm 7.2(60-93)$ & $69.2 \pm 7.6(60-91)$ & $69.1 \pm 7.4(60-93)$ \\
\hline \multicolumn{4}{|l|}{ Age group (yr) } \\
\hline $60-64$ & $74(34.1)$ & $50(34.5)$ & $124(34.3)$ \\
\hline $65-69$ & $46(21.2)$ & $30(20.7)$ & $76(21.0)$ \\
\hline$\geq 75$ & $48(22.1)$ & $35(24.1)$ & $83(22.9)$ \\
\hline Weight* (kg) & $59.6 \pm 10.5(31.0-102.5)$ & $67.9 \pm 11.9(39.7-108.0)$ & $62.9 \pm 11.8(31.0-108.0)$ \\
\hline Height* (cm) & $154.0 \pm 5.8(141.0-176.5)$ & $163.1 \pm 7.1(140.9-181.5)$ & $157.6 \pm 7.8(140.9-181.5)$ \\
\hline \multicolumn{4}{|l|}{ Residence } \\
\hline Urban & 159 (73.3) & $93(64.1)$ & $252(69.6)$ \\
\hline Suburban/rural & $58(26.7)$ & $52(35.9)$ & $110(30.4)$ \\
\hline Chinese & $155(71.4)$ & $90(62.1)$ & $245(67.7)$ \\
\hline Malay & $36(16.6)$ & $34(23.4)$ & $70(19.3)$ \\
\hline Indian & $22(10.1)$ & $20(13.8)$ & $42(11.6)$ \\
\hline Others & $4(1.8)$ & $1(0.7)$ & $5(1.4)$ \\
\hline
\end{tabular}

*Data presented as mean \pm standard deviation (range).

a fixed position. Walking ability and dynamic balance were assessed using the TUG test. ${ }^{(25)}$

All collected data was analysed using IBM SPSS Statistics version 21.0 (IBM Corp, Armonk, NY, USA). Categorical variables were presented as frequency (percentage). Continuous variables were initially evaluated using histogram plots and the Kolmogorov-Smirnov test to determine normal distribution. Variables that were normally distributed were presented as mean \pm SD. Variables that were not normally distributed were presented as median (interquartile range). The hand strength (i.e. HGS and KPS) results were first presented according to age group and gender, in mean \pm SD and 95\% confidence interval (to represent normal ranges). These values were then descriptively compared with international reference norms. Independent $t$-test was used to compare hand strength between male and female, and urban and suburban/rural participants. Analysis of variance was used to compare hand strength among age groups and ethnicities. The JTHFT score was transformed into a normally distributed variable by calculating the inverse JTHFT (i.e. 1/JTHFT). The correlations between hand strength with age, 1/JTHFT, FRT and TUG were assessed using Pearson's correlation test. A p-value $<0.05$ was considered statistically significant.

\section{RESULTS}

A total of 362 right-hand-dominant participants were recruited for the study. The characteristics of the participants according to gender are listed in Table I, and their performance on the FRT, TUG test and JTHFT is shown in Table II.

For hand strength analysis, the 362 participants were divided into four groups based on age: (a) 60-64 years $(\mathrm{n}=124)$; (b) 65-69 years $(\mathrm{n}=76)$; (c) 70-74 years $(\mathrm{n}=79)$; and $(d) \geq 75$ years $(n=83)$. As hand strength was distributed normally, mean \pm SD and $95 \%$ confidence interval were used to describe the results. The HGS and KPS of the participants,
Table II. Performance of the participants on the Functional Reach Test (FRT), Timed Up and Go (TUG) test and Inverse Jebsen-Taylor Hand Function Test (JTHFT).

\begin{tabular}{lc}
\hline Test & Score (mean \pm SD) \\
\hline FRT $(\mathbf{c m})$ & $28.1 \pm 8.0$ \\
TUG test (s) & $12.6 \pm 5.5$ \\
JTHFT (s) & \\
$\quad$ Right hand & $58.6 \pm 23.8$ \\
Left hand & $89.0 \pm 32.2$ \\
Inverse JTHFT* (/s) & \\
$\quad$ Right hand & 0.017066 \\
Left hand & 0.011235 \\
\hline
\end{tabular}

*Data presented as mean. SD: standard deviation

according to age and gender, are presented in Tables III and IV. In general, the men were stronger than the women in both HGS and KPS $(p<0.001)$. There were significant differences in HGS and KPS among the age groups $(p<0.001)$. Hand strength appeared to decline with age, with the youngest age group having the greatest hand strength.

Both HGS and KPS were significantly higher among the participants who lived in suburban/rural areas as compared to those in urban areas (independent $t$-test, $\mathrm{p}<0.001$ ) (Table V). Based on the results of analysis of variance, there was a significant difference in the HGS of the right hand among the ethnicities $(p=0.006)$. Using Tukey's test for post-hoc analysis, we found that the Chinese participants had significantly greater HGS of the right hand than the Indian participants (mean difference $5.08 \pm 1.53 \mathrm{~kg}$, $\mathrm{p}=0.005$ ); comparisons among the other ethnicities did not reveal any significant difference.

HGS was strongly and positively correlated with KPS in the present study (right hand: $r=0.824, p<0.001$; left hand: $r=0.817$, $p<0.001)$. The correlations between hand strength and other variables are shown in Table VI. A moderate inverse association 
Table III. Hand grip strength (HGS), according to age and gender $(n=362)$.

\begin{tabular}{|c|c|c|c|c|c|}
\hline \multirow[t]{3}{*}{ Age group (yr) } & \multirow[t]{3}{*}{ Gender } & \multicolumn{4}{|c|}{ HGS (kg) } \\
\hline & & \multicolumn{2}{|c|}{ Right hand } & \multicolumn{2}{|c|}{ Left hand } \\
\hline & & Mean \pm SD & $95 \% \mathrm{Cl}$ & Mean \pm SD & $95 \% \mathrm{Cl}$ \\
\hline \multirow[t]{2}{*}{$60-64$} & Male $(n=50)$ & $39.5 \pm 7.6$ & $37.1-41.7$ & $36.6 \pm 7.6$ & $34.1-38.7$ \\
\hline & Female $(n=74)$ & $26.0 \pm 5.5$ & $24.0-27.2$ & $23.9 \pm 5.2$ & $21.7-24.6$ \\
\hline \multirow[t]{2}{*}{$65-69$} & Male $(n=30)$ & $34.2 \pm 8.0$ & $30.5-37.4$ & $31.0 \pm 7.5$ & $27.4-34.0$ \\
\hline & Female $(n=46)$ & $22.3 \pm 5.8$ & $20.5-26.7$ & $20.4 \pm 6.1$ & $18.4-24.8$ \\
\hline \multirow[t]{2}{*}{$70-74$} & Male $(n=30)$ & $31.1 \pm 8.4$ & $27.2-35.1$ & $28.0 \pm 7.5$ & $24.3-31.3$ \\
\hline & Female $(n=49)$ & $20.5 \pm 4.2$ & $19.5-23.2$ & $18.8 \pm 4.4$ & $18.1-21.5$ \\
\hline \multirow[t]{2}{*}{$\geq 75$} & Male $(n=35)$ & $24.5 \pm 6.6$ & $22.3-27.2$ & $22.1 \pm 6.5$ & $20.2-24.9$ \\
\hline & Female $(n=48)$ & $17.4 \pm 4.2$ & $16.9-19.9$ & $15.5 \pm 4.1$ & $15.0-17.8$ \\
\hline
\end{tabular}

$\mathrm{Cl}$ : confidence interval; SD: standard deviation

Table IV. Key pinch strength (KPS), according to age and gender $(n=246)$.

\begin{tabular}{|c|c|c|c|c|c|}
\hline \multirow[t]{3}{*}{ Age group (yr) } & \multirow[t]{3}{*}{ Gender } & \multicolumn{4}{|c|}{ KPS (kg) } \\
\hline & & \multicolumn{2}{|c|}{ Right hand } & \multicolumn{2}{|c|}{ Left hand } \\
\hline & & Mean \pm SD & $95 \% \mathrm{Cl}$ & Mean \pm SD & $95 \% \mathrm{Cl}$ \\
\hline \multirow[t]{2}{*}{$60-64$} & Male $(n=44)$ & $9.8 \pm 1.7$ & $9.3-10.3$ & $8.9 \pm 1.6$ & $8.4-9.4$ \\
\hline & Female $(n=47)$ & $7.0 \pm 1.2$ & $6.7-7.4$ & $6.4 \pm 1.0$ & $6.1-6.7$ \\
\hline $65-69$ & Male $(n=26)$ & $8.4 \pm 2.1$ & $7.6-9.2$ & $8.0 \pm 1.6$ & $7.3-8.6$ \\
\hline \multirow[t]{2}{*}{$70-74$} & Male $(n=21)$ & $8.6 \pm 2.2$ & $7.6-9.6$ & $7.8 \pm 1.9$ & $7.0-8.7$ \\
\hline & Female $(n=26)$ & $6.2 \pm 1.5$ & $5.6-6.9$ & $5.9 \pm 1.6$ & $5.2-6.5$ \\
\hline \multirow[t]{2}{*}{$\geq 75$} & Male $(n=26)$ & $7.5 \pm 1.6$ & $6.8-8.1$ & $6.9 \pm 1.6$ & $6.2-7.5$ \\
\hline & Female $(n=34)$ & $5.7 \pm 1.2$ & $5.2-6.1$ & $5.3 \pm 1.1$ & $4.9-5.7$ \\
\hline
\end{tabular}

Data on 116 participants was not collected. Cl: confidence interval; SD: standard deviation

Table V. Hand strength of the participants, according to their area of residence $(n=362)$.

\begin{tabular}{|c|c|c|c|}
\hline \multirow[t]{2}{*}{ Variable } & \multicolumn{2}{|c|}{ Mean \pm standard deviation } & \multirow[t]{2}{*}{ p-value } \\
\hline & Urban $(n=252)$ & Suburban/rural $(n=110)$ & \\
\hline \multicolumn{4}{|c|}{ Hand grip strength (kg) } \\
\hline Right hand & $24.4 \pm 8.5$ & $31.2 \pm 9.2$ & $<0.001$ \\
\hline Left hand & $21.8 \pm 7.8$ & $29.5 \pm 9.0$ & $<0.001$ \\
\hline \multicolumn{4}{|c|}{ Key pinch strength (kg) } \\
\hline Left hand & $6.7 \pm 1.7$ & $7.6 \pm 2.0$ & $<0.001$ \\
\hline
\end{tabular}

Table VI. Correlation of hand strength with age, and the results of the inverse Jebsen-Taylor Hand Function Test (JTHFT), Functional Reach Test (FRT) and Timed Up and Go (TUG) test.

\begin{tabular}{|c|c|c|c|c|c|c|c|c|}
\hline \multirow[t]{3}{*}{ Variable } & \multicolumn{4}{|c|}{ Hand grip strength } & \multicolumn{4}{|c|}{ Key pinch strength } \\
\hline & \multicolumn{2}{|c|}{ Right } & \multicolumn{2}{|c|}{ Left } & \multicolumn{2}{|c|}{ Right } & \multicolumn{2}{|c|}{ Left } \\
\hline & $\mathbf{r}$ & p-value & $\mathbf{r}$ & p-value & $\mathbf{r}$ & p-value & $\mathbf{r}$ & p-value \\
\hline Age & -0.439 & $<0.001$ & -0.450 & $<0.001$ & -0.351 & $<0.001$ & -0.351 & $<0.001$ \\
\hline Inverse JTHFT & -0.927 & $<0.001$ & - & - & - & - & - & - \\
\hline FRT & 0.236 & 0.028 & - & - & - & - & - & - \\
\hline
\end{tabular}

was observed between age and HGS (right hand: $r=-0.439$, $\mathrm{p}<0.001$; left hand: $r=-0.450, \mathrm{p}<0.001)$. The HGS of the right hand was also found to be significantly correlated with participants' performance in the FRT $(r=0.236, p=0.028)$ and TUG test $(r=-0.227, p=0.009)$, although the magnitude of the correlations was fair. We observed a strong inverse correlation between HGS of the right hand and the inverse JTHFT ( $r=-0.927, p<0.001)$.

The hand strength of the participants in the present study was compared to international norms reported in studies performed in the United States, ${ }^{(26)}$ Switzerland, ${ }^{(13)}$ Korea, ${ }^{(17)}$ Canada $^{(11)}$ and 


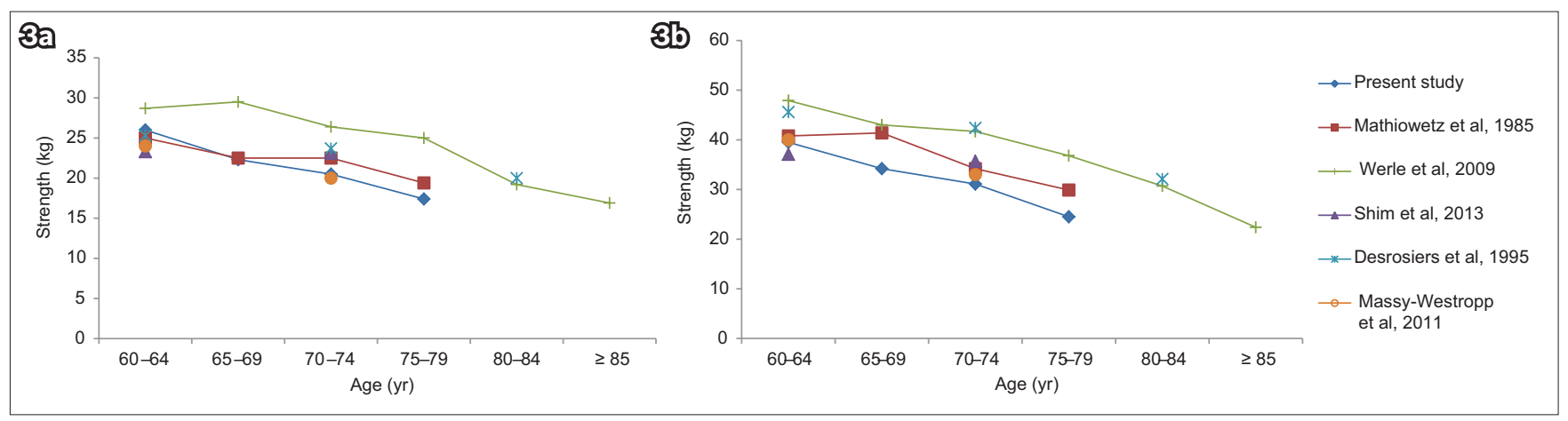

Fig. 3 Line graphs show the hand grip strength of the right hand of the participants compared with international norms, for (a) women and (b) men.

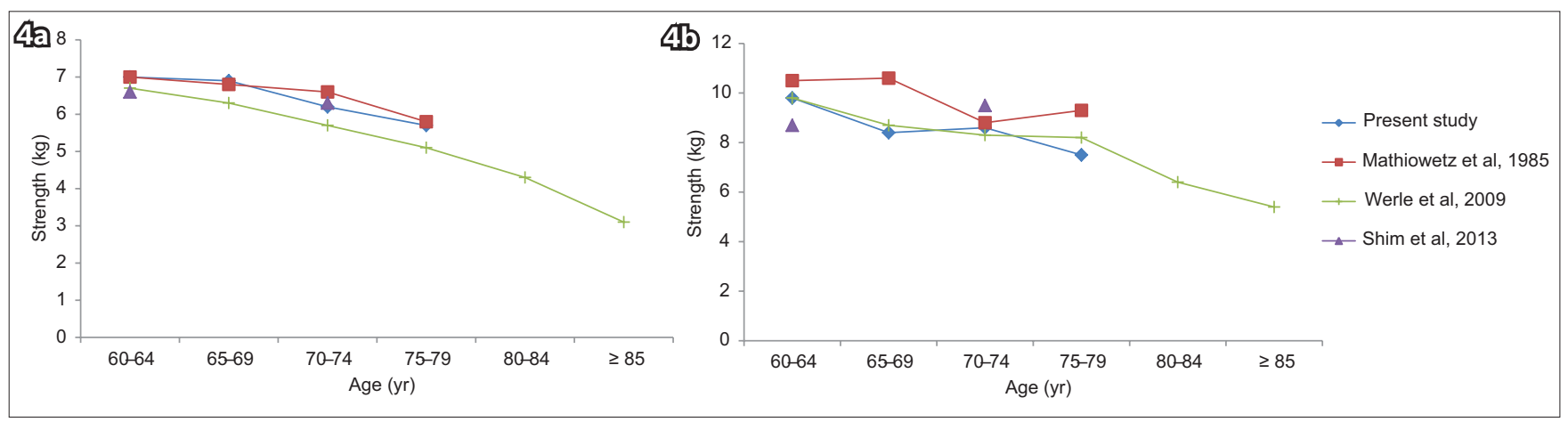

Fig. 4 Graphs show the key pinch strength of the right hand of the participants compared with international norms, for (a) women and (b) men.

northwest Adelaide. ${ }^{(12)}$ Figs. 3 and 4 illustrate the differences in hand strength between the populations. Table VII shows the calculated ratios of the international reference HGS and KPS values (published by Mathiowetz et al) ${ }^{(26)}$ to the HGS and KPS values of the present study, which ranged from 0.87-1.26. $A$ ratio of one indicated that there was no difference in mean hand strength between the international reference and Malaysian participants in the present study, while ratios $<1$ suggested that the Malaysian participants had greater hand strength.

\section{DISCUSSION}

The present study aimed to address the lack of standardised hand strength norms in Malaysia, by developing normative data for upper limb strength in Malaysians aged $\geq 60$ years. The values we obtained represent normal ranges and do not take into account other factors that could have influenced hand strength, such as body weight and height, occupation and comorbidities. As the presence of comorbidities increases markedly with age, it was not possible for us to only include individuals without any comorbidity. Hypertension, hypercholesterolaemia, diabetes mellitus and osteoarthritis are conditions that are highly prevalent in older populations. Limiting recruitment to individuals without these medical conditions would be extremely challenging and also result in the collection of data that is not representative of the norm in our older population.

In our study, hand strength significantly declined with increasing age and was significantly higher among men. These findings were consistent with previous studies and expected physiological variations. ${ }^{(11,13,14,17,20,26)}$ However, a possible influence on this trend may be the growing role of women in the development of modern society, leading to major changes in the activity patterns of both genders. Hence, future studies may need to be conducted to update these normative values.

Interestingly, we observed a significant difference in the HGS of participants from different ethnic groups in the present study. These differences have not been explored previously, as previous studies did not involve multiethnic populations. The present study was not powered to determine the potential contributing factors to HGS variation among the different ethnic groups. Differences in ethnicity are associated with variations in genetic makeup as well as cultural practices. Genetic makeup influences body habitus and physical composition, while cultural practices influence physical activity, nutritional intake and occupational factors. As the Chinese, Malay and Indian ethnic groups are all of Asian descent, few variations in physical size and strength were expected. The relationship between ethnicity and HGS, therefore, represents a complex and interesting area of research that needs to be explored in the future. The unique ethnic composition of the participants in the present study suggests that the normal ranges derived from this study may have a much wider relevance than those previously published; this is especially the case since $31 \%$ of older people in the world are from China and India. (27)

Differences in the hand strength of persons living in urban areas and those in rural areas have not been evaluated and should be the subject of future research studies. The finding that the HGS and KPS of the older rural population were greater than those of older urban dwellers in Malaysia was in line with our expectations. A probable explanation for this observation is that the main midlife occupations of persons living in rural areas were manual tasks, such as farming and rubber tapping, while 
Table VII. Ratio of the international reference hand grip strength and key pinch strength values (published by Mathiowetz et al)(26) to the values in the present study.

\begin{tabular}{|c|c|c|c|c|c|c|c|c|}
\hline \multirow[t]{3}{*}{ Age group (yr) } & \multicolumn{4}{|c|}{ Hand grip strength } & \multicolumn{4}{|c|}{ Key pinch strength } \\
\hline & \multicolumn{2}{|c|}{ Male } & \multicolumn{2}{|c|}{ Female } & \multicolumn{2}{|c|}{ Male } & \multicolumn{2}{|c|}{ Female } \\
\hline & Right & Left & Right & Left & Right & Left & Right & Left \\
\hline $60-64$ & 1.03 & 0.95 & 0.96 & 0.87 & 1.07 & 1.13 & 1.00 & 1.00 \\
\hline $65-69$ & 1.21 & 1.13 & 1.01 & 0.90 & 1.26 & 1.25 & 0.99 & 1.00 \\
\hline $70-74$ & 1.10 & 1.05 & 1.10 & 1.01 & 1.02 & 1.12 & 1.06 & 1.07 \\
\hline$\geq 75$ & 1.22 & 1.13 & 1.11 & 1.10 & 1.24 & 1.26 & 1.02 & 0.98 \\
\hline
\end{tabular}

that of persons living in urban areas tended to be sedentary, deskbound occupations. Elderly persons from rural areas appeared to have a greater reserve of strength as a result of the greater occupational demands on their hands during midlife. Previous epidemiological studies have highlighted major differences between the health-related indices of urban and rural populations, with rural populations consistently faring worse in such health indicators. ${ }^{(28)}$ The urban-rural divide in health status in Malaysia has yet to be adequately addressed. Changes in demographics due to the migration of the younger generation from rural to urban areas have led to the presence of a larger older population in rural areas. This is concerning, as it increases the healthcare burden, resulting in increased healthcare costs for this older population. However, if hand strength is considered a good marker of frailty among older adults, our findings that elderly persons from rural areas have greater hand strength may be reassuring.

The FRT and TUG test are both well-established tests that are frequently used in research as a marker of physical frailty, functional mobility and fall risk in older individuals. ${ }^{(25,29)}$ In the present study, right HGS was found to be significantly correlated with results of the FRT and TUG test. The FRT, TUG test and HGS measurement are all parameters that can be used to assess elderly health status and disability. The significant correlation between HGS and the results of these tests in the present study support the role of HGS as a frailty indicator. The near-perfect correlation between HGS and JTHFT ( $r=-0.927)$ validates HGS as a highly accurate marker of overall hand function. This finding also indicates that HGS, which is a quick and easy test, can be used to replace JTHFT, which is a far more complicated and time-consuming test, as a measure of hand function.

When the hand strength values of the present study were compared with those published by Mathiowetz et al, ${ }^{(26)}$ the ratios obtained indicate that Malaysian women aged 60-69 years are as strong as, if not stronger than, the corresponding population in their study (ratios of 0.87-1.01); similarly, Malaysian women aged $\geq 70$ years are nearly as strong as the corresponding population (ratios of 1.0-1.1). On the other hand, older Malaysian men in the present study scored slightly poorer than the corresponding population in Mathiowetz et al's study, with ratios of 0.95-1.10 in the 60-69 years age group and ratios of 1.10-1.26 in the $\geq 75$ years age group. In a study by Kamarul et al that examined the HGS of younger Malaysians (age $\leq 65$ years), the authors found that the HGS of the corresponding population in Mathiowetz et al's study was up to 1.5 times greater than that of their study cohort. ${ }^{(20)}$ The better scores attained among the older Malaysians in the present study may reflect the changing economic structure of Malaysia, as the main occupations of older Malaysians include manual tasks such as farming, rubber tapping and tin mining, whereas younger Malaysians tend to have more sedentary occupations in factories and offices, in keeping with the industrialisation of the country. However, Flood-Joy and Mathiowetz reported incorrect calibration in one of the instruments used to measure grip strength among their older participants, ${ }^{(30)}$ which may have compromised the outcome of the normal value obtained for the older participants.

The present study was not without limitations. The participants were not a nationally representative sample selected through a sampling frame. They were recruited from Klang Valley, Selangor, Malaysia, and Bahau, Negeri Sembilan, Malaysia, among the country's thirteen states and three federal territories, hence may not have been representative of the Malaysian population. Nonetheless, it was assumed that a broad range of socioeconomic groups was recruited, as the participants were from rural, suburban and urban areas. Although a nationally representative sample using a sampling frame would have been useful, it would have been prohibitively expensive for our study.

Another limitation was the ethnic distribution of the participants. The majority of our participants were Chinese (67.7\%), followed by Malays (19.3\%) and Indians (11.6\%). The ethnic composition of the Malaysian population for these three ethnic groups, as of July 2010, is as follows: Malays (60.3\%), Chinese $(22.9 \%)$ and Indians (7.1\%). ${ }^{31)}$ While the ethnic composition of the Malaysian elderly population (i.e. aged $\geq 60$ years) is not readily available, the proportion of older Chinese and Indians are expected to be far higher in the older Malaysian population, as the life expectancies for ethnic Chinese men and women are 74.4 years and 78.9 years, respectively, while the life expectancies for ethnic Malay men and women are 70.5 years and 75.3 years, respectively. ${ }^{(32)}$ Projected figures in 1998 estimated that $14.4 \%$ of Chinese will be aged $\geq 60$ years by 2020 , as compared to $10.4 \%$ of Indians and $7.9 \%$ of Malays. ${ }^{(33)}$ The dwindling proportion of ethnic Chinese and Indians in our population is also influenced by declining birth rates and outward migration. Thus, the over-representation of Chinese in the older population of this study is consistent with the ageing demographics of Malaysia.

The Baseline pinch gauge used in the present study malfunctioned toward the end of the data collection phase. This 
unforeseen issue resulted in fewer data points on KPS ( $n=246$, instead of $n=362$ ). Although we believe that the true values were unaffected, this can only be verified through future studies. We suggest that further research is conducted to update the population-specific hand strength norms in the future, as Malaysia is a growing and developing country that may undergo significant epidemiological changes in the future. Any potential changes in the normative data will impact the applicability of the current normal ranges.

In conclusion, this study presents normative data on HGS and KPS among older Malaysians. The hand strength norms we obtained were lower than the international reference values, highlighting the importance of population-specific norms. HGS appears to be a valid substitute for JTHFT in its ability to provide an overall measure of hand function, and was also found to correlate significantly with lower limb gait and balance measures, as measured by the FRT and TUG test. We also found that HGS was significantly different among the different ethnic groups and between the urban and rural populations. Future studies should seek to determine potentially modifiable risk factors for reduced hand strength and explore the role of HGS as a triage, screening and/or resource management tool in the healthcare setting.

\section{ACKNOWLEDGEMENTS}

The authors wish to thank the volunteers for their participation in this study and the Ageing and Age-Associated Disorders Research Group for their contribution to the fieldwork. This research was funded by a University of Malaya Research Grant (RP-010-2012) and Post Graduate Research Fund (No. P0045-2013).

\section{REFERENCES}

1. Arokiasamy JT. Malaysia's ageing population: challenges in the new millenium. Med J Malaysia 1999; 54:429-32.

2. Fried LP, Tangen CM, Walston J, et al; Cardiovascular Health Study Collaborative Research Group. Frailty in older adults: evidence for a phenotype. J Gerontol A Biol Sci Med Sci 2001; 56:M146-56.

3. Christensen K, Doblhammer G, Rau R, Vaupel JW. Ageing populations: the challenges ahead. Lancet 2009; 374:1196-208.

4. Giampaoli S, Ferrucci L, Cecchi F, et al. Hand-grip strength predicts incident disability in non-disabled older men. Age Ageing 1999; 28:283-8.

5. Gale CR, Martyn CN, Cooper C, Sayer AA. Grip strength, body composition, and mortality. Int J Epidemiol 2007; 36:228-35.

6. Rantanen T, Volpato S, Ferrucci L, et al. Handgrip strength and causespecific and total mortality in older disabled women: exploring the mechanism. J Am Geriatr Soc 2003; 51:636-41.

7. Sasaki H, Kasagi F, Yamada M, Fujita S. Grip strength predicts causespecific mortality in middle-aged and elderly persons. Am J Med 2007; 120:337-42.

8. Keevil V, Mazzuin Razali R, Chin AV, et al. Grip strength in a cohort of older medical inpatients in Malaysia: a pilot study to describe the range, determinants and association with length of hospital stay. Arch Gerontol Geriatr 2013; 56:155-9.

9. Roberts HC, Syddall HE, Cooper C, Aihie Sayer A. Is grip strength associated with length of stay in hospitalised older patients admitted for rehabilitation?
Findings from the Southampton grip strength study. Age Ageing 2012; 41:641-6.

10. Kellor M, Frost J, Silberberg N, Iversen I, Cummings R. Hand strength and dexterity. Am J Occup Ther 1971; 25:77-83.

11. Desrosiers J, Bravo G, Hébert R, Dutil E. Normative data for grip strength of elderly men and women. Am J Occup Ther 1995; 49:637-44.

12. Massy-Westropp NM, Gill TK, Taylor AW, Bohannon RW, Hill CL. Hand Grip Strength: age and gender stratified normative data in a populationbased study. BMC Res Notes 2011; 4:127.

13. Werle S, Goldhahn J, Drerup S, et al. Age- and gender-specific normative data of grip and pinch strength in a healthy adult Swiss population. J Hand Surg Eur Vol 2009; 34:76-84.

14. Günther CM, Bürger A, Rickert M, Crispin A, Schulz CU. Grip strength in healthy caucasian adults: reference values. J Hand Surg Am 2008; 33:558-65.

15. Härkönen R, Piirtomaa M, Alaranta H. Grip strength and hand position of the dynamometer in 204 Finnish adults. J Hand Surg Br 1993; 18:129-32.

16. Mitsionis G, Pakos EE, Stafilas KS, et al. Normative data on hand grip strength in a Greek adult population. Int Orthop 2009; 33:713-7.

17. Shim JH, Roh SY, Kim JS, et al. Normative measurements of grip and pinch strengths of 21 st century korean population. Arch Plast Surg 2013; 40:52-6.

18. Chong CK, Tseng CH, Wong MK, Tai TY. Grip and pinch strength in Chinese adults and their relationship with anthropometric factors. J Formos Med Assoc 1994; 93:616-21.

19. Pieterse S, Manandhar M, Ismail S. The association between nutritional status and handgrip strength in older Rwandan refugees. Eur J Clin Nutr 2002; 56:933-9.

20. Kamarul T, Ahmad TS, Loh WY. Hand grip strength in the adult Malaysian population. J Orthop Surg (Hong Kong) 2006; 14:172-7.

21. Fess EE, Moran C. Clinical assessment recommendations. Indianapolis: American Society of Hand Therapists Monograph, 1981.

22. Fess EE. The effects of Jamar dynamometer handle position and test protocol on normal grip strength. J Hand Surg 1981; 7:308-9.

23. Jebsen RH, Taylor N, Trieschmann RB, Trotter MJ, Howard LA. An objective and standardized test of hand function. Arch Phys Med Rehabil 1969; 50:311-9.

24. Duncan PW, Weiner DK, Chandler J, Studenski S. Functional reach: a new clinical measure of balance. J Gerontol 1990; 45:M192-7.

25. Podsiadlo D, Richardson S. The timed "Up \& Go": a test of basic functional mobility for frail elderly persons. J Am Geriatr Soc 1991; 39:142-8.

26. Mathiowetz V, Kashman N, Volland G, et al. Grip and pinch strength: normative data for adults. Arch Phys Med Rehabil 1985; 66:69-74.

27. World Health Organization. Global Health and Aging [online]. Available at: http://www.who.int/ageing/publications/global_health.pdf. Accessed October 23, 2015.

28. Eberhardt MS, Pamuk ER. The importance of place of residence: examining health in rural and nonrural areas. Am J Public Health 2004; 94:1682-6.

29. Weiner DK, Duncan PW, Chandler J, Studenski SA. Functional reach: a marker of physical frailty. J Am Geriatr Soc 1992; 40:203-7.

30. Flood-Joy M, Mathiowetz V. Grip-strength measurement: a comparison of three Jamar dynamometers. Occ Ther J Res 1987; 7:235-43.

31. Department of Statistics Malaysia. Population and Housing Census Malaysia 2010 -Population Distribution and Basic Demographic Characteristic Report 2010. In: Department of Statistics Malaysia, Official Portal [online]. Available at: https://www.statistics.gov.my/ index.php? $r=$ column/cthemeByCat\&cat $=117 \& b u l \_i d=M D M x d H$ ZjWTk1SjFzTzNkRXYzcVZjdz09\&menu_id=LOpheU43NWJwRWVSZkIW dzQ4TIhUUT09. Accessed August 12, 2014.

32. Department of Statistics Malaysia. Abridges Life Tables, Malaysia 20082010. In: Deprtment of Statistics Malaysia, Official Portal [online]. Available at: https://www.statistics.gov.my/dosm/images/stories/files/ LatestReleases/abridged/Abridged_Life_Tables_2008-2010.pdf. Accessed August 30, 2014.

33. Ong FS, Phillips DR, Tengku-Aizan H. Ageing in Malaysia: Progress and prospects. In: Fu TH, Hudges R, eds. Ageing in East Asia: Challenges and policies for the twenty-first century. London: Routledge, 2009: 138-60. 